\title{
Extraoral tumor-like granuloma as a symptom of dental infection: A case report
}

\author{
Sanne Werner Madsen*1, Sara Taylor Søgaard ${ }^{2}$, Grethe Schmidt ${ }^{3}$, Morten Schiodt ${ }^{1}$ \\ ${ }^{1}$ Department of Oral and Maxillofacial Surgery, Rigshospitalet, Copenhagen University Hospital, Blegdamsvej 92100 København \\ $\varnothing$, Denmark \\ ${ }^{2}$ Private practice, Copenhagen, Kronprinsessegade 46, 1306 København K, Denmark \\ ${ }^{3}$ Department of Plastic Surgery, Breast Surgery and Burns Treatment, Rigshospitalet, Copenhagen University Hospital, \\ Blegdamsvej 92100 København $\varnothing$, Denmark
}

Received: March 19, 2016

DOI: $10.5430 /$ crcp.v3n3p23
Accepted: May 2, $2016 \quad$ Online Published: May 16, 2016

URL: http://dx.doi.org/10.5430/crcp.v3n3p23

\begin{abstract}
A 26-year-old woman with a cutaneous granuloma and fistula caused by a dental infection was initially mistaken for a tumor. She was under diagnostic examinations at several health care providers for 1.5 years before a final diagnosis and treatment was reached. The fistula originated from a periapical lesion and extended to the facial skin. Differential diagnoses include malignant tumor, bacterial infection, furuncle and a granulomatous-like lesion. When a patient is presented with a fistula or granuloma-like lesion on the cheek, chin or the submandibular region, a dental infection should always be suspected. Relevant imaging of the teeth and jaws will usually reveal the cause. The medical history, the oral and skin findings, biopsy, imaging results and treatment are presented in this article.
\end{abstract}

Key Words: Cutaneous fistula, Extraoral fistula, Dental infection, Periapical infection, Tumor-like granuloma

\section{INTRODUCTION}

Diagnosing the etiology of a cutaneous fistula can be a challenge. ${ }^{[1-11]}$ Cutaneous fistulas may look like a tumor or granuloma and therefore can be mistaken initially for furuncle, bacterial infection of a sebaceous gland, carcinoma, pyogenic granuloma, congenital fistulae, tuberculosis or other granulomatous lesions. ${ }^{[1-11]}$ It is important that the oral surgeon/dentist and physician interact in order to avoid unnecessary, ineffective or inappropriate treatment. Approximately half of the patients with cutaneous fistula are often misdiagnosed. ${ }^{[1,3,4]}$ The reason for misdiagnosing might be that other similar looking lesions may appear on the skin of the face and neck, and that an odontogenic infection causing the lesion is not generally suspected. If a fistula is excised and the cause is not recognized, it will inevitably recur. ${ }^{[2,3]}$

A cutaneous fistula may originate from an infected tooth. ${ }^{[5,10]}$ Infection in a tooth leads to a necrotic pulp and periapical infection may develop more acutely into an abscess (either submucosal or subcutaneous) or may take a more chronic course with development of a fistula (sinus tract) through which pus may drain. ${ }^{[6,7]}$ In this case the symptoms are less severe and the disease course may be prolonged over many months. A dental fistula will often appear on the oral mucosa, and more uncommonly on the skin. ${ }^{[6]}$

The site of extraoral penetration of the sinus depends on the tooth, the relation between facial and cervical anatomy, the muscle attachment and the virulence of the microorgan-

*Correspondence: Sanne Werner Madsen; Email: sanne@w-madsen.dk; Address: Gunløgsgade 3, 4 tv, 2300 København S, Denmark. 
isms. ${ }^{[2,4]}$

The cause of odontogenic cutaneous sinus tracts is known to be a result of a dental infection. The tooth may be asymptomatic due to necrosis of the pulp. The onset of cutaneous sinus tracts is often associated with swelling and pain in the cheek or chin, and the patient may not recall or be aware of any dental problems and therefore seek treatment from a physician, general practitioner, dermatologist, plastic surgeon or other health care professional. ${ }^{[3,8]}$

A clinical study including 200 patients has shown that $80 \%$ of extraoral fistula had dental origin, and only $20 \%$ had nondental origin. In $14 \%$ of the cases the sinus tract was in the maxillary region, $83 \%$ in the mandibular region and $2 \%$ in the cervical region. ${ }^{[8]}$ The sinuses are most common seen in the submandibular and submental region. ${ }^{[2,5,7,9,10]}$

Diagnosis of a dental origin includes medical history, clinical examination and radiographic examinations (panoramic radiographs, periapical radiographs and/or Cone Beam Tomography (CBT)). ${ }^{[9]}$ The clinical findings of necrotic pulp can be verified by a negative electronic pulp test of the affected tooth. The radiographs will show a periapical radiolucent area around the tooth and loss of lamina dura.

The treatment aims to remove the source of the infection. First choice of treatment will be an orthograde root filling or extraction of the tooth. ${ }^{[2]}$ With a successful treatment a spontaneous closure of the fistula will often be seen within 5-14 days. ${ }^{[2-4]}$ Surgical intervention with excision of the fistula is often not necessary but depends of the disease course. ${ }^{[1,2,7,9,11]}$

\section{Case presentation}

A 26-year-old woman was referred to the Department of Oral \& Maxillofacial Surgery from Department of Plastic Surgery, Breast Surgery and Burns Treatment, with a tumor on the left cheek region of 1.5 years duration (see Figure 1). She was complaining of pain, growth of the tumor and bothered from an unpleasant esthetic appearance. Prior to the referral at Department of Oral \& Maxillofacial Surgery she had numerous appointments, imaging and biopsies. Her medical history included: Eight extraoral and one intraoral fine-needle biopsies which all showed acellular material, an inconclusive CT-Scan and a knife biopsy in local analgesia showing infection consistent with granulomatous tissue. Finally a MRI scan was performed and showed a fistula from the left maxillary sinus or from the apex of a tooth (see Figure 2). The patient was then referred to Department of Oral \& Maxillofacial Surgery.

The clinical examination at the Department of Oral \& Maxillofacial Surgery, Rigshospitalet, revealed a protruding welldefined $1 \mathrm{~cm}$ tumor resembling granulation tissue with a secreting fistula. Extraoral palpation revealed a fistula in the cheek, going from the left lateral part of the maxilla (tooth $25)$ to the cheek surface. Pulp test on the left second premolar was negative but intraorally there were no signs of infection (see Figure 3). A panoramic radiograph did not reveal any apical pathology (see Figure 4). Additional CBT showed an apical radiolucency $0.5 \mathrm{~cm} \times 0.5 \mathrm{~cm}$ at the apex of the second left premolar (see Figure 5). The clinical examination and imaging lead to the diagnosis chronic apical periodontitis of tooth 25 with an extraoral fistula.

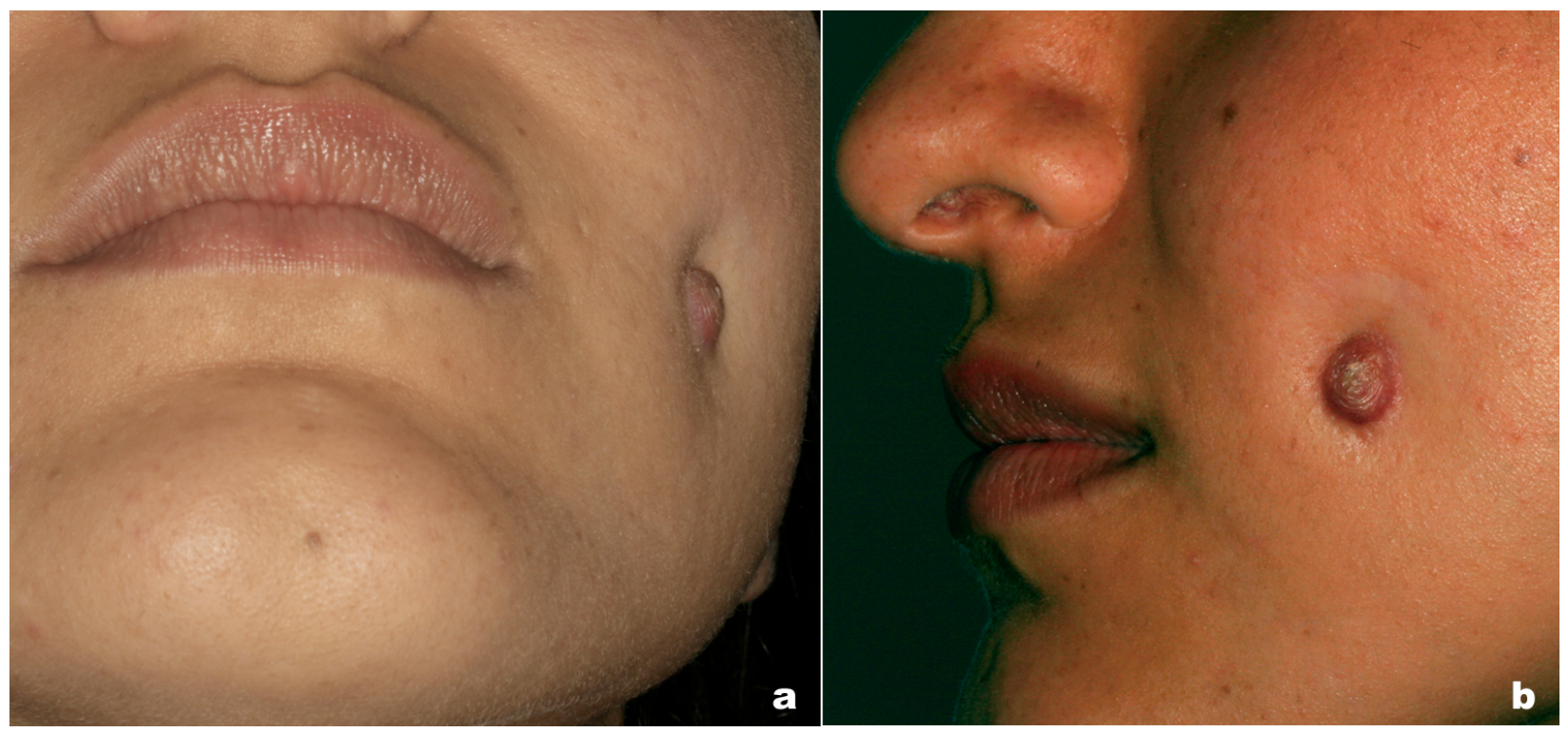

Figure 1. Tumor-like change on the left cheek at time of admission in a 26-year-old woman 


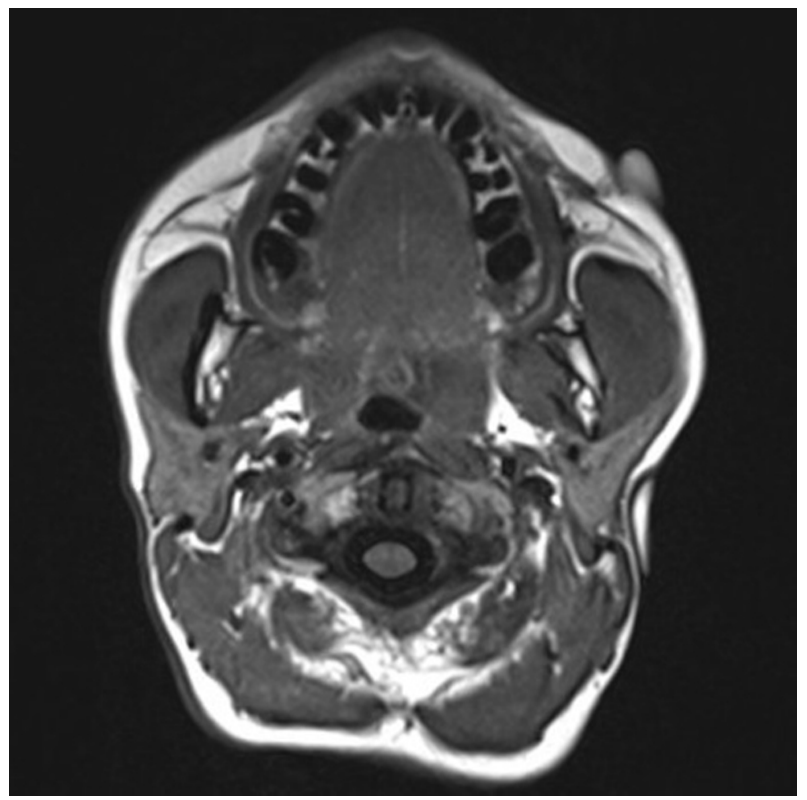

Figure 2. MR-scan shows a fistula starting from tooth 25

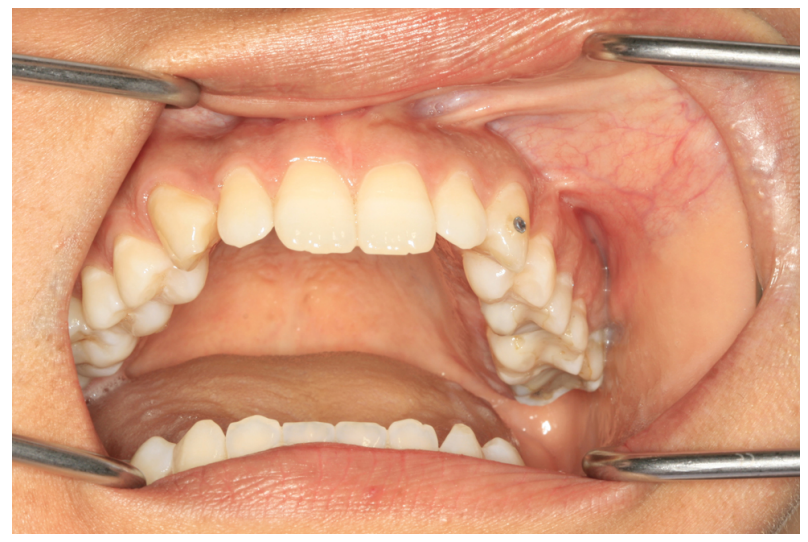

Figure 3. No sign of pathology intraorally

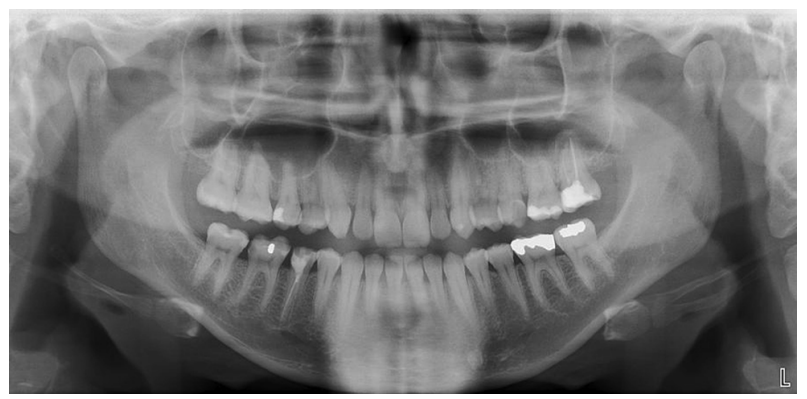

Figure 4. No apparent sign of apical pathology on tooth 25, but signs of chronic apical periodontitis on tooth 27

The tooth was treated endodontically with an orthograde root filling (see Figure 6) and subsequently she had a root resection and retrograde root filling combined with excision of the fistula by blunt dissection through the cheek and excision Published by Sciedu Press of the extraoral granuloma (see Figures 7-10). Healing was uneventful and at 3-month follow-up the extra- and intraoral scar tissue was nearly invisible. The patient had no symptoms and the radiograph did not show any signs of infection (see Figures 11-12).

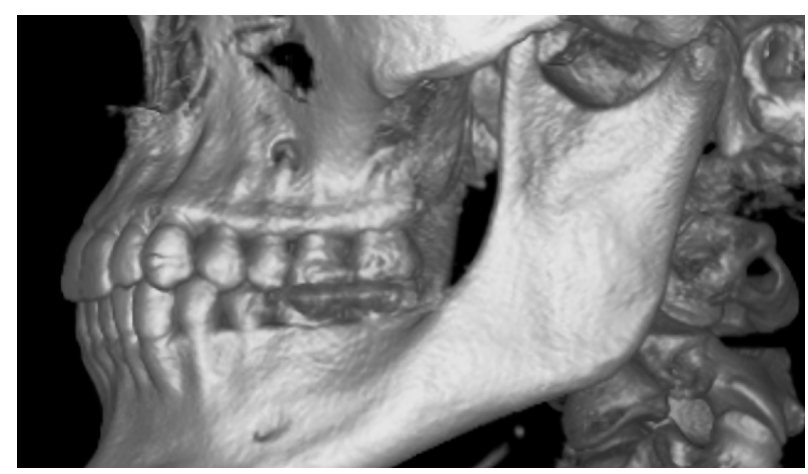

Figure 5. CBT scan show apical pathology on tooth 25

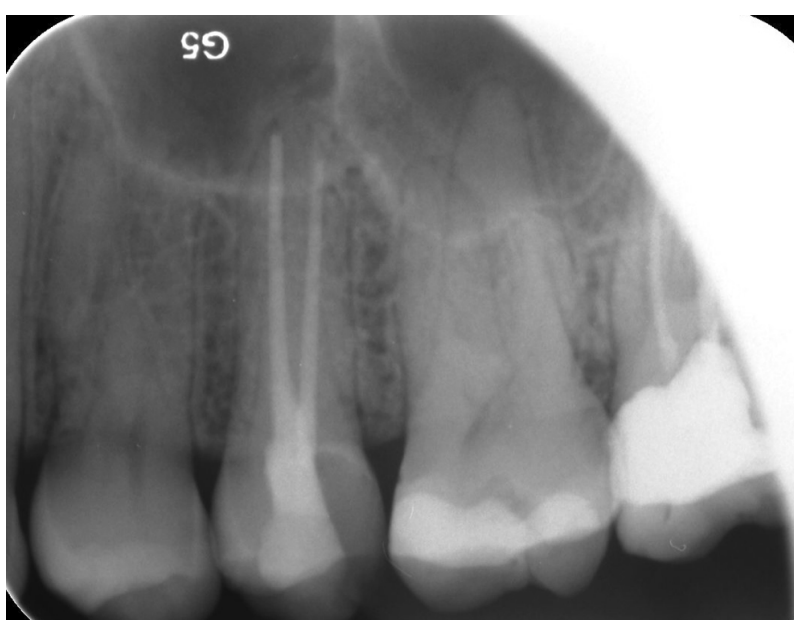

Figure 6. Sufficient endodontic treatment of 25

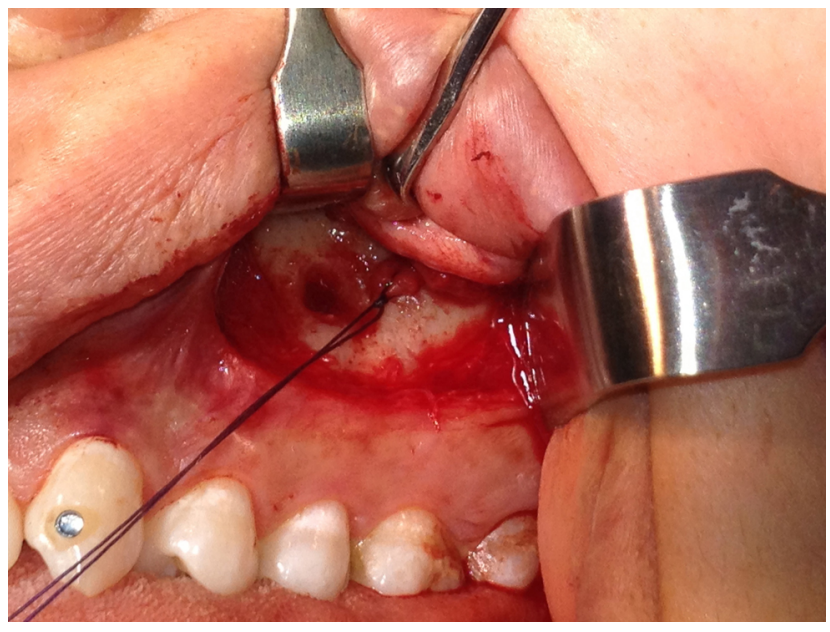

Figure 7. Intraoral fenestration of the facial cortical lamella of the maxillary bone at the apex of tooth 25 , a suture is placed around the fistula to facilitate the blunt dissection 


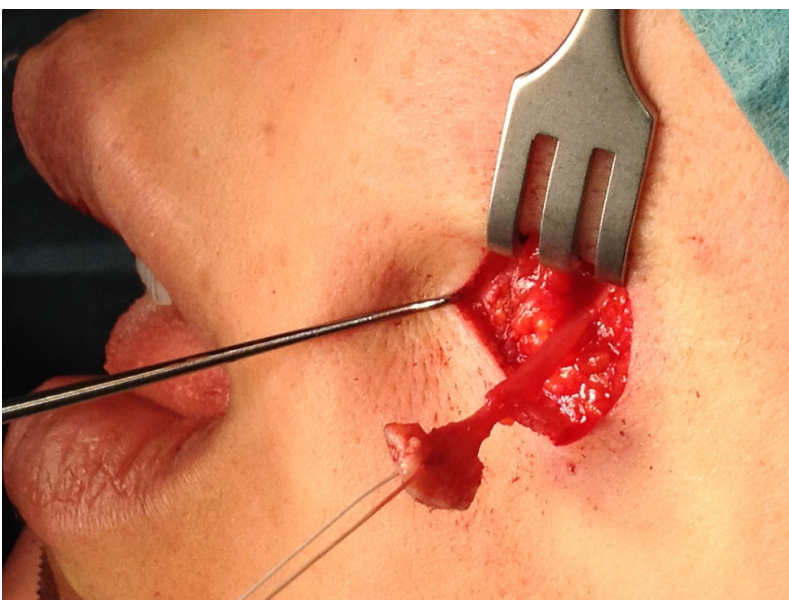

Figure 8. Extraoral view of the excision of the cutaneous granuloma and the dissection of the fistula. A suture is placed in the cutaneous end of the fistula to facilitate the dissection.

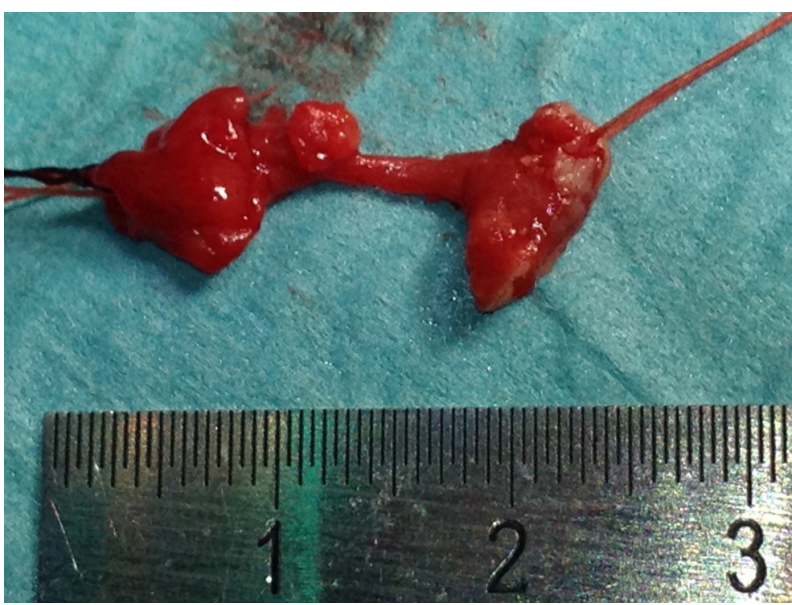

Figure 9. Excision specimen of the granuloma and the fistula. The extraoral end is to the right and the mucosal end to the left, in the middle the sinus tract.

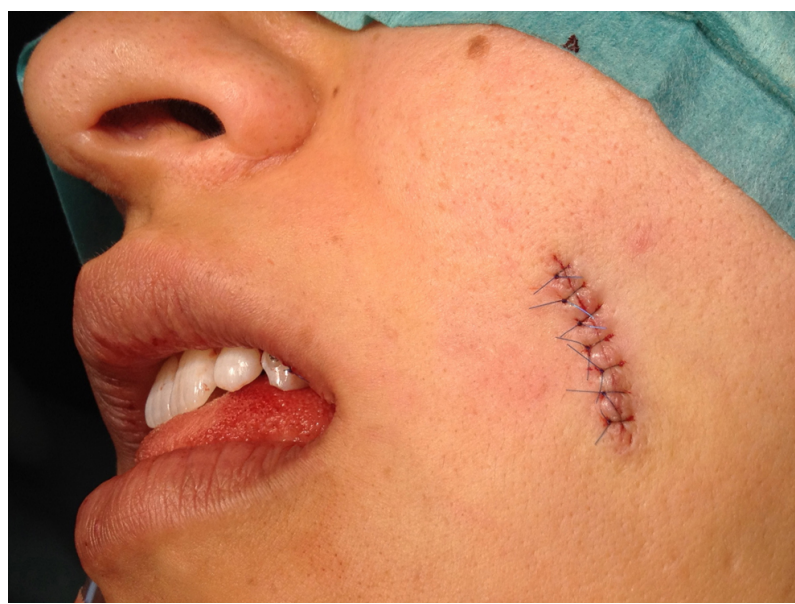

Figure 10. Extraoral closure after excision of the granuloma

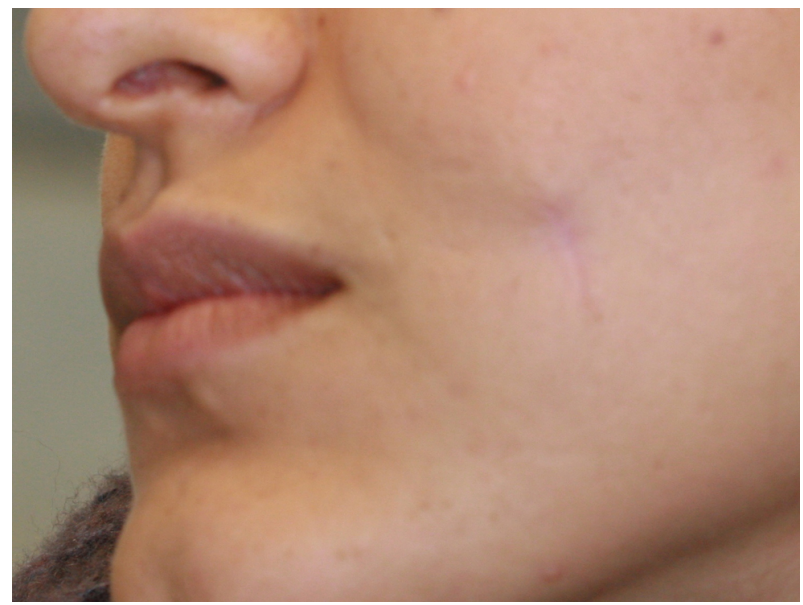

Figure 11. Three month follow-up, the patient had no sign of infection and showed minimal scar tissue

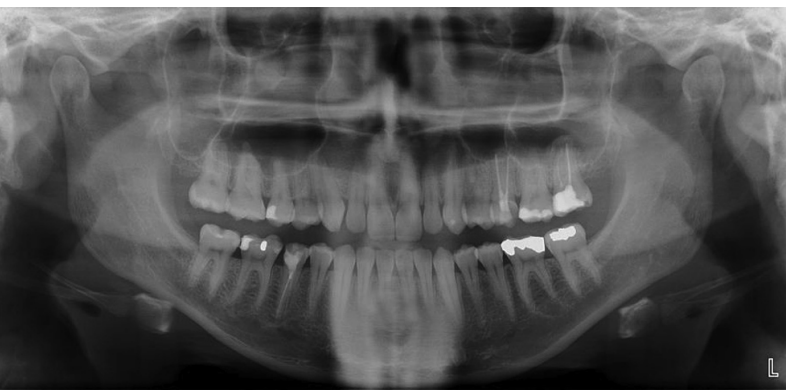

Figure 12. Ortopantomography shows healing at the apex of tooth 25 and no sign of pathology around tooth 25

\section{Discussion}

This case-report highlights the need of considering a dental focus when a patient is presenting with a tumor-like fistula in the cervico-facial region. A periodontal infection may lead to abscess or a fistula formation which can originate on the oral mucosa or the facial skin. ${ }^{[11]}$ There are many differential diagnoses and a dental infection may not initially be suspected and thus delaying the correct treatment. ${ }^{[5]}$

When the fistula drains extraorally and the patient has no symptoms, the patient often seeks a general practitioner or a dermatologist. ${ }^{[3]}$ At this point a referral to a dentist is recommended. ${ }^{[3]}$ If no dental foci are found a biopsy should be made.

In the present case the periodontal infection was not visible on the panoramic radiograph although suspected. Therefore a supplementary image procedure was done and CBT revealed a clear periodontal infection. This documents the limitations of radiographs only revealing a 2-dimensional picture of the bone.

Treatment of the extraoral fistula is based on elimination and clearance of the source of the infection. The primary choice 
of treating an extraoral fistula with dental origin should be endodontic treatment or extraction of the tooth. ${ }^{[2]}$ Endodontic treatment often leads to resolution of the fistula within 2 weeks. ${ }^{[2,4,7]}$ In the present case the fistula was extensive and the cosmetic disfigurement of the face required a surgical intervention. ${ }^{[11]}$ Resection of the apex of the tooth also removes the granulation tissue around the apex and the retrograde root filling secures a tight root canal sealing at the apex of the tooth. Thereby the risk of recurrence will be lowered.

\section{Conclusion}

Diagnosing the etiology of extraoral fistula in the cervicofacial region can be difficult. An odontogenic origin should always be considered. A clinical examination followed by conventional x-ray should be the first choice. A resolution of the fistula will often be seen after relevant endodontic treatment. Tumor-like granuloma and fistula may require surgical excision in addition to endodontic treatment. Multiple biopsies, antibiotic treatments, X-ray exposing and prolonged time before the correct diagnosis and treatment is made, can be avoided if the cause is considered to be of odontogenic origin.

\section{CONFLicts OF InTEREST Disclosure}

No actual or potential conflict of interest including any financial, personal or other relationships with other people or organizations within three years of beginning the submitted work that could inappropriately influence, or be perceived to influence my work.

\section{REFERENCES}

[1] Bai J, Ji AP, Huang MW. Submental cutaneous sinus tract of mandibular second molar origin. International endodontic journal. 2014; 47(12): 1185-91. PMid: 24697494. http://dx.doi.org/10.11 $11 /$ iej. 12266

[2] Johnson BR, Remeikis NA, Van Cura JE. Diagnosis and treatment of cutaneous facial sinus tracts of dental origin. Journal of the American Dental Association (1939). 1999; 130(6): 832-6. http://dx.doi.org/10.14219/jada.archive.1999.0307

[3] Sammut S, Malden N, Lopes V. Facial cutaneous sinuses of dental origin - a diagnostic challenge. British dental journal. 2013; 215(11): 555-8. PMid: 24309783. http://dx. doi .org/10.1038/sj . bdj . 2013. 1141

[4] Pasternak-Junior B, Teixeira CS, Silva-Sousa YT, et al. Diagnosis and treatment of odontogenic cutaneous sinus tracts of endodontic origin: three case studies. International endodontic journal. 2009; 42(3): 271-6. PMid: 19228218. http://dx.doi.org/10.1111/j .1365-2591.2008.01519.x

[5] Gimenez-Garcia R, Martinez-Vera F, Fuentes-Vera L. Cutaneous Sinus Tracts of Odontogenic Origin: Two Case Reports. Journal of the American Board of Family Medicine: JABFM. 2015; 28(6): 838-40. PMid: 26546662. http://dx.doi.org/10.3122/jabfm. 2015. 06.150046

[6] Brown RS, Jones R, Feimster T, et al. Cutaneous sinus tracts (or emerging sinus tracts) of odontogenic origin: a report of 3 cases.
Clinical, cosmetic and investigational dentistry. 2010; 2: 63-7. http://dx.doi.org/10.2147/CCIDEN.S6472

[7] Soares JA, de Carvalho FB, Pappen FG, et al. Conservative treatment of patients with periapical lesions associated with extraoral sinus tracts. Australian endodontic journal: the journal of the Australian Society of Endodontology Inc. 2007; 33(3): 131-5. PMid: 18076581. http://dx.doi.org/10.1111/j.1747-4477.2007.00058.x

[8] Kishore KRV, Devireddy SK, Gali RS, et al. Cutaneous sinuses of cervicofacial region: a clinical study of 200 cases. Journal of maxillofacial and oral surgery. 2012; 11(4): 411-5. PMid: 24293932. http://dx.doi.org/10.1007/s12663-012-0353-y

[9] Abuabara A, Schramm CA, Zielak JC, et al. Dental infection simulating skin lesion. Anais brasileiros de dermatologia. 2012; 87(4): 619-21. PMid: 22892779. http://dx.doi.org/10.1590/S0365 $-05962012000400017$

[10] Tian J, Liang G, Qi W, et al. Odontogenic cutaneous sinus tract associated with a mandibular second molar having a rare distolingual root: a case report. Head \& face medicine. 2015; 11: 13. PMid: 25885921. http://dx.doi.org/10.1186/s13005-015-0072-y

[11] Cohenca N, Karni S, Rotstein I. Extraoral sinus tract misdiagnosed as an endodontic lesion. Journal of endodontics. 2003; 29(12): 841-3. PMid: 14686820. http://dx.doi.org/10.1097/00004770-2 00312000-00015 